\title{
PROCESSO ELEITORAL DEMOCRÁTICO E AS ONDAS DE DIREITOS POLÍTICOS DAS MULHERES
}

RESUMO: Este artigo, revisando bibliografia e jurisprudência, foca decisão recente do Supremo Tribunal Federal, abordando o movimento crescente, embora lento, de modificação do Direito para incluir mulheres na política. Busca também aferir se essa nova onda é capaz de efetivar o eixo teórico de igualdade substancial e erradicação da discriminação. Outro objetivo é verificar se há regras e princípios dotados de autonomia tal que sustente nova disciplina, o direito político das mulheres. A importância do trabalho é patente diante da diversidade cultural brasileira, revelando promessa incumprida, como se conclui, com oferta de alteração da realidade para mitigar o deficit apresentado.

Palavras - chave: Diversidade cultural; Mulheres na política; Erradicação da discriminação; Direito das mulheres; Igualdade concreta.

\section{DEMOCRATIC ELECTORAL PROCESS AND WOMEN'S POLITICAL RIGHTS WAVES}

\begin{abstract}
This article, revising bibliography and jurisprudence, focus on recent ruling of Brazil's Supreme Court approaching the increasing movement, although slow, of change in Law to include women in politics. It also tries to gauge if this new-wave is capable of making real the theoretical axis of substantive-equality and prejudice eradication. Another objective is to verify the existence of autonomous rules and principles that sustain this new discipline, the political right of women. The work's importance is evident in face of the Brazilian cultural diversity; reveals an unfulfilled promise, as concluded; and offers immediate reality change to mitigate the presented deficit.
\end{abstract}

Keywords: Cultural diversity; Women in politics; Prejudice eradication; Women's rights; Concrete equality.

\footnotetext{
${ }^{1}$ Doutora em Direito Processual (PUCMINAS). Mestre em Direito Administrativo (UFMG). Especialista em Processo Penal (UNIVERSIDAD CASTILLA LA MANCHA). Professora do Mestrado em Proteção de Direitos Fundamentais da Universidade de Itaúna. Advogada.
} 


\section{INTRODUÇÃO}

A Constituição brasileira assinala, como fundamento da República, a promoção do bem de todos, sem discriminações (art. $3^{\circ}, \mathrm{IV}$ ), afirmando que homens e mulheres são iguais em direitos e obrigações (art. $\left.5^{\circ}, \mathrm{I}\right)$.

Essa igualdade legal não se materializa no mundo da vida (plano concreto), particularmente no campo da política. Tanto assim que a lei eleitoral, no formato atual, fixa cota de 30\% dos cargos levados a registro para candidaturas do "sexo minoritário" (Lei 9.504/97, art. 10, $\S 3^{\circ}$ ), destinando-se às mulheres, mesmo sem denominá-las como tal, porque é notória sua ausência da vida pública.

A despeito dessa cota, o ostracismo da mulher na política brasileira é registrado em números atuais eloquentes.

Nas eleições de 2014, apenas 9,94\% da Câmara dos Deputados² era de mulheres e $18,5 \%$ do Senado $^{3}$, acompanhando a eleição da primeira mulher para presidir o Brasil, Dilma Roussef, cassada no ano seguinte, em resposta sexista a questões políticas ${ }^{4}$.

Em 2016, nas eleições municipais ${ }^{5}$, 52\% do eleitorado era do sexo feminino, correspondendo a 75.226.056 mulheres, mas somente 11,57\% do total de chefes do executivo pertence às mulheres, com 640 prefeitas eleitas. As vereadoras eleitas no mesmo ano correspondem a 13,5\% do total, com 7.811 parlamentares municipais em todo o País.

Recentemente, ganhou o mundo o assassinato da vereadora carioca Marielle Franco ${ }^{6}$, em 14 de março de 2018, em pleno centro da capital do Rio de Janeiro, ativista pela participação da mulher na política, "vítima da mais cruel e covarde forma de discriminação que é a eliminação física”7.

\footnotetext{
${ }^{2}$ BRASIL. Câmara dos Deputados. Bancada feminina cresce de 45 para 51 Deputadas. Relatório divulgado em 06 de outubro de 2014. Disponível em:< http://www2.camara.leg.br/camaranoticias/noticias/POLITICA/475459BANCADA-FEMININA-CRESCE-DE-45-PARA-51-DEPUTADAS.html >. Acesso: 01 abr. 2018.

${ }^{3}$ BAPTISTA, Rodrigo. Cresce percentual de mulheres entre Senadores eleitos. Brasília: Senado, 06 de outurbo de 2014. Disponível em:< https://www12.senado.leg.br/noticias/materias/2014/10/06/cresce-percentual-demulheres-entre-senadores-eleitos >. Acesso: 01 abr. 2018.

${ }^{4}$ LOBO, Edilene. O (des)controle judicial do impeachment. Brasilia: Universitas Jus, v. 27, no 3, 2017, p. 7-16.

${ }^{5}$ Resultado divulgado pelo Tribunal Superior Eleitoral. Disponível em: < http://www.tse.jus.br/eleitor-eeleicoes/estatisticas/eleicoes/eleicoes-anteriores/estatisticas-eleitorais-2016/resultados>. Acesso em 27 mar. 2018.

${ }^{6}$ Marielle Franco foi a quinta vereadora mais bem votada e a segunda com o maior número de votos dentre as oito eleitas num universo de 51 cadeiras disponíveis no legislativo municipal.

${ }^{7}$ MORAES, Alexandre de. Ministro do Supremo Tribunal Federal, quando do voto na sessão de 15 de março de 2018, julgando procedente a ADI n ${ }^{\circ}$ 5.617. Disponível em: <https://www.youtube.com/watch?v=-P7TrXk63Zs . Acesso: 27 mar. 2018.
} 
A propósito do assassinato das mulheres, a partir de dados da Organização Mundial da Saúde, a ONU registra que no Brasil “a taxa de feminicidios é de 4,8 para cada 100 mil

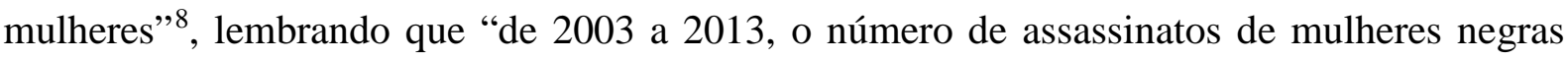
cresceu 54\%"9!

No campo profissional em geral, pesquisa realizada pela CATHO, divulgada pelo portal eletrônico G1, em reportagem de Marta Cavallini ${ }^{10}$, aponta que em todas as faixas de escolarização, as mulheres continuam recebendo remuneração menor que os homens:

\section{Diferença de salários por escolaridade Pesquisa leva em conta a média salarial, em R\$}
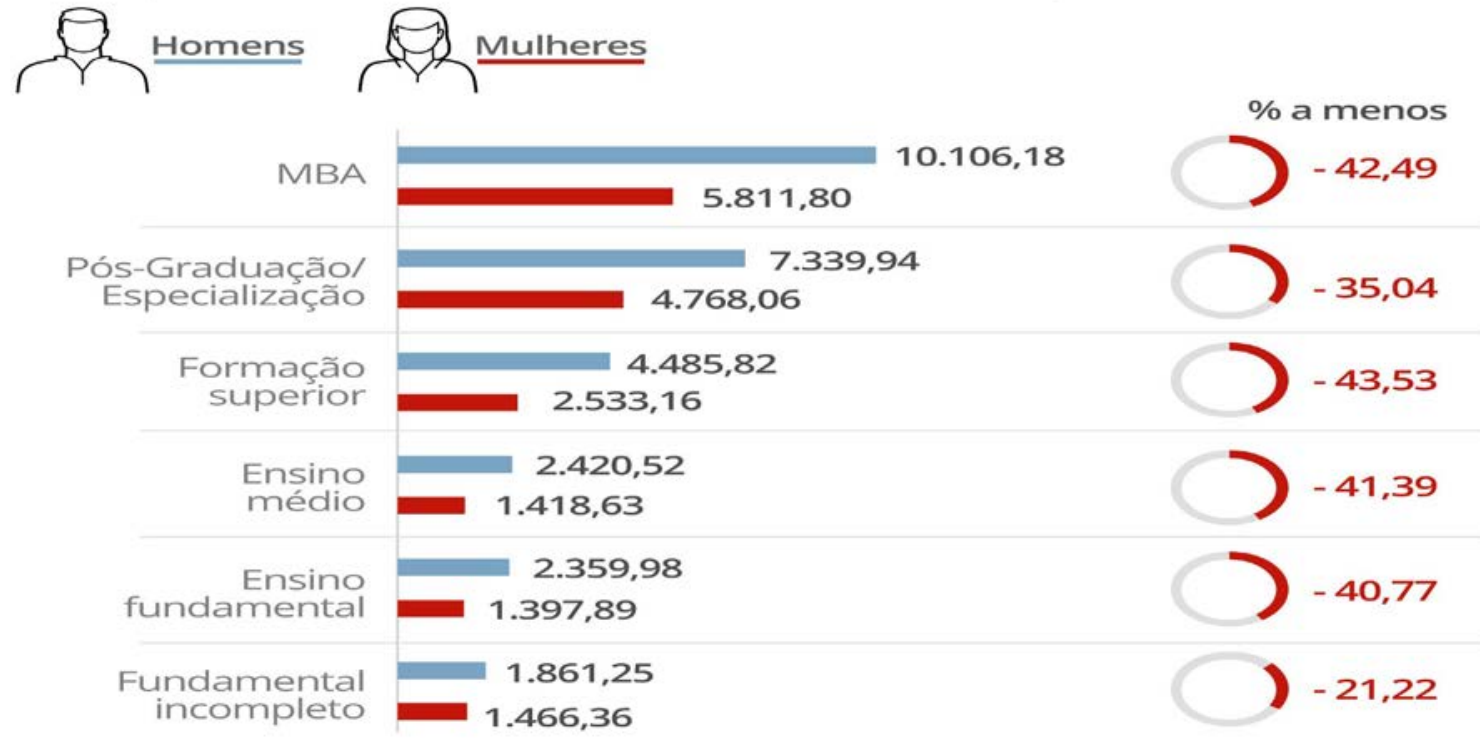

Fonte: Catho

Na atividade jurídica, conforme dados da Caixa de Assistência os Advogados de Minas Gerais, "as advogadas representam mais de $48 \%$ dos inscritos na OAB e a previsão é de que esse número se equipare nos próximos anos. Dentro dos cursos de direito, elas já são a maioria:

\footnotetext{
${ }^{8}$ ONU. Taxa de feminicidios no Brasil é quinta maior do mundo. Publicado em 09 de abril de 2016. Disponível em: <https://nacoesunidas.org/onu-feminicidio-brasil-quinto-maior-mundo-diretrizes-nacionais-buscamsolucao/>. Acesso: 27 mar. 2018.

${ }^{9}$ ONU. Taxa de feminicidios no Brasil é quinta maior do mundo. Publicado em 09 de abril de 2016. Disponível em: <https://nacoesunidas.org/onu-feminicidio-brasil-quinto-maior-mundo-diretrizes-nacionais-buscamsolucao/>. Acesso: 27 mar. 2018.

${ }^{10}$ CAVALLINI, Marta. Mulheres ganham menos que os homens em todos os cargos e áreas. O Globo: Portal G1, Rio de Janeiro, 2018. Disponível em:<https://g1.globo.com/economia/concursos-eemprego/noticia/mulheres-ganham-menos-que-os-homens-em-todos-os-cargos-e-areas-diz-pesquisa.ghtml>. Acesso em 27 mar. 2018.
} 
55\% dos estudantes”11. Todavia, “a sub-representação estende-se ao órgão de classe onde, mesmo com esforços e medidas de combate à desigualdade de gênero, a representatividade feminina dentro de seus quadros é de 37\% - ainda que, como inscritas, elas já sejam a maioria entre os advogados de até 40 anos de idade.”12

No ambiente forense não há qualquer contraste com a realidade em outras áreas, porque “apenas 26,2\% de mulheres compõem a magistratura federal” ${ }^{13}$, sendo que "Na Justiça Estadual, são 34,5\% de juízas” ${ }^{14}$, havendo exceção somente na Justiça do Trabalho, em que os números apontam para algum equilíbrio com os homens, com “47\% de mulheres entre os magistrados" ${ }^{15}$.

Na academia também não há contraste em tais números.

Pesquisa divulgada pela Capes $^{16}$ dá conta de que “doutoras tituladas no exterior representam, desde 2012, mais de 60\% dos brasileiros que obtiveram esse título em outros países” ${ }^{17}$. Todavia, a remuneração oferecida a elas é em média 83,5\% da oferecida aos homens com a mesma titulação. Isso quer dizer que "ganham em média R \$ 15.239,12, enquanto os homens com a mesma titulação recebem em média, por mês, R\$ 18.250,49”18.

Nessa quadra, a disparidade é acachapante e permite reconhecer que eventuais ações afirmativas ainda não contam com os mecanismos capazes de transformar os números apresentados, muito embora se veja lento processo de modificação do statu quo, por vezes em retromarcha pela ação violenta.

\footnotetext{
${ }^{11}$ CAIXA DE ASSISTÊNCIA DOS ADVOGADOS - MG. Mulher advogada: igualdade ou o machismo perdura? Disponível em: < https:/www.caamg.org.br/mulher-advogada-igualdade>. Acesso em 27 mar. 2018.

12 CAIXA DE ASSISTÊNCIA DOS ADVOGADOS - MG. Mulher advogada: igualdade ou o machismo perdura? Disponível em: < https:/www.caamg.org.br/mulher-advogada-igualdade>. Acesso em 27 mar. 2018. ${ }^{13}$ NEISCHT, Joana. Mulheres são apenas 26,2\% da magistratura federal. Jornal Gazeta do Povo. Em 08 de março de 2018. Disponível em:< http://www.gazetadopovo.com.br/vida-p ublica/justica-e-direito/mulheres-saoapenas-262-da-magistratura-federal-f3p3x3enzs47wzpei1m9v96w3>. Acesso: 27 mar. 2018.

${ }^{14}$ NEISCHT, Joana. Mulheres são apenas 26,2\% da magistratura federal. Jornal Gazeta do Povo. Em 08 de março de 2018. Disponível em:< http://www.gazetadopovo.com.br/vida-p ublica/justica-e-direito/mulheres-saoapenas-262-da-magistratura-federal-f3p3x3enzs47wzpei1m9v96w3>. Acesso: 27 mar. 2018.

${ }^{15}$ NEISCHT, Joana. Mulheres são apenas 26,2\% da magistratura federal. Jornal Gazeta do Povo. Em 08 de março de 2018. Disponível em:< http://www.gazetadopovo.com.br/vida-p ublica/justica-e-direito/mulheres-saoapenas-262-da-magistratura-federal-f3p3x3enzs47wzpei1m9v96w3>. Acesso: 27 mar. 2018.

${ }^{16}$ CAPES. Estudo aponta que mulheres lideram número de doutores titulados no exterior. Disponível em: < https://capes.gov.br/component/content/article/36-salaimprensa/noticias/7852-estudo-aponta-que-mulhereslideram-numero-de-doutores-titulados-no-exterior>. Acesso em: 29 mar. 2018.

${ }^{17}$ CAPES. Estudo aponta que mulheres lideram número de doutores titulados no exterior. Disponível em: < https://capes.gov.br/component/content/article/36-salaimprensa/noticias/7852-estudo-aponta-que-mulhereslideram-numero-de-doutores-titulados-no-exterior>. Acesso em: 29 mar. 2018.

${ }^{18}$ CAPES. Estudo aponta que mulheres lideram número de doutores titulados no exterior. Disponível em: < https://capes.gov.br/component/content/article/36-salaimprensa/noticias/7852-estudo-aponta-que-mulhereslideram-numero-de-doutores-titulados-no-exterior>. Acesso em: 29 mar. 2018.
} 
A despeito disso, no que se refere aos direitos tangendo a participação política das mulheres, desde a conquista do voto feminino por aqui, não se pode negar que há um estatuto jurídico em construção.

Previsões legais expressas tutelando os direitos das mulheres inverte a história de invisibilidade e de sujeição ao poder patriarcal, revelando que o tempo da insignificância e da desigualdade precisa ser superado. Por isso, o reconhecimento da existência de conjunto de regras e princípios tutelando os direitos políticos das mulheres é eixo para a deflagração de ações estratégicas afirmativas da paridade no provimento de cargos políticos, possibilitando alguma contribuição ao campo do direito construído ao longo de milênios quase que exclusivamente pelos homens.

A mais nova onda, assim, é a paridade democrática para partilha da vida boa prometida.

Com essa proposta, o presente artigo se divide em três partes:

a) ondas de direitos políticos das mulheres;

b) cotas e igualdade substancial: partida e chegada;

c) o estatuto político das mulheres.

Adotando o método dedutivo hipotético, lançando mão da revisão bibliográfica e jurisprudencial, sob os influxos do paradigma constitucional da erradicação da discriminação e da desigualdade, chegou-se às conclusões ofertadas ao final.

Busca-se, no ponto fulcral deste trabalho, reconhecer que a diversidade cultural, assim como a anatômica, política, religiosa ou qualquer outra assimetria que distinga as pessoas, não são capazes de sustentar a desigualdade abissal entre homens e mulheres no Brasil. Urgindo, assim, modificação da realidade, que caminha em passos largos de volta à barbárie, a manter o cenário atual de exterminação física e a alienação política das mulheres.

\section{AS ONDAS DE DIREITOS POLÍTICOS DAS MULHERES ${ }^{19}$}

\footnotetext{
${ }^{19}$ A escolha do substantivo posto no título para tratar do assunto se deveu à inspiração da música de Lulu Santos, “como uma onda”, que diz da oferta de mudança do statu quo "o tempo todo, no mundo”, "num indo e vindo infinito”, como é o movimento da vida e da luta das mulheres. Também porque onda é substantivo feminino que traduz a força das marés, outro substantivo feminino, influenciado por outro substantivo feminino, a lua, que encarna o divino feminino e regula os ciclos da vida, esta outro substantivo feminino. Tratar o movimento jurídico cíclico, às vezes em marcha para trás, que envolve a luta das mulheres por reconhecimento e inclusão como se fossem ondas, parece bastante oportuno para o objetivo central do trabalho. Adotar linguagem poética no estudo de tema tão denso reafirma o equilíbrio que a paridade encerra. Ondas vão e vão, marés reguladas pela lua orientam o ciclo da vida em busca de equidade e balanceamento. É o que se defende.
} 
Pode-se dizer que a primeira onda envolvendo direitos políticos da mulher no Brasil se deu com a luta pelo voto feminino, que culminou no artigo $2^{\circ}$ do Decreto $n^{\circ} 21.076$, de 24 de fevereiro de 1932, garantindo o voto sem discriminações de gênero no Código Eleitoral da época: "É eleitor o cidadão maior de 21 anos, sem distinção de sexo, alistado na forma deste Código.” (BRASIL, 1932).

A segunda grande onda foi inaugurada com a viragem jurídico-política inaugurada com a Constituição de 1988, que encartou a igualdade e a erradicação da discriminação sexual como fundamentos da República (art. $3^{\circ}$, IV), assinalando que homens e mulheres são iguais em direitos e obrigações (art. $5^{\circ}$, I). Essa onda só chegou depois de longos retrocessos com as ditaduras do Estado Novo em 1937 e a Militar em 1964, entremeadas por curtos lapsos democráticos.

A terceira onda com a fixação de cotas para o registro de candidatas a cargos legislativos, na versão inicial, se fez presente na Lei nº 9.100, de 1995, até então prevista para as eleições municipais, “cujo $\S 3^{\circ}$ do artigo 11 estabeleceu a obrigação de se preencherem vagas de vinte por cento para mulheres, nas chapas de candidatos proporcionais” (LOBO, 2016, p. 44). Essa onda segue movimento internacional deflagrado na Europa vinte e cinco anos antes (DAHLERUP, 1999).

Dois anos depois, com a edição da Lei Geral das Eleições, de nº 9.504, de 1997, o § $3^{\circ}$ do artigo 10 fixou reserva de mínimo de 30\% e máximo de 70\% para candidaturas de cada sexo. Nesse novo texto houve modificação no tratamento da matéria, porque “além da redação, também o percentual foi alterado, não mais se tratando de 'vagas para mulheres'. O destaque (...) é para o verbo reservar e a expansão do mínimo” (LOBO, 2016, p. 44). Mesmo assim, a praxis não privilegiava a disposição legal, porque só se reservavam as vagas, sem preenchimento efetivo dos cargos em disputa, até então não havendo mecanismo capaz de efetivar a pretensa ação afirmativa à participação na disputa eleitoral.

Seguiu-se à reforma de 2009 a Lei $\mathrm{n}^{0}$ 12.034, restabelecendo o verbo imperativo preencher, egresso da redação anterior de 1995, deixando o § $3^{\circ}$ do artigo 10 da lei 9.504 da seguinte forma: “cada partido ou coligação preencherá o mínimo de 30\% (trinta por cento) e o máximo de 70\% (setenta por cento) para candidaturas de cada sexo” (BRASIL, 2009). “Sem dubiedade, a ordem era para que se adotasse a proporcionalidade, ao menos no registro de candidatos - embora sem qualquer garantia de vagas no Parlamento.” (LOBO, 2016, p. 44) 
Na reforma de 2015, com a Lei $\mathrm{n}^{0} 13.165$, aparentemente se buscava garantir recursos financeiros para as campanhas eleitorais das mulheres fixando piso de $5 \%$ e teto de $15 \%$ do Fundo Partidário para as três eleições seguintes, mas deixando ao talante das direções partidárias a acumulação de tais recursos para aplicação em futuro incerto. Essa proposta vai se apresentar como retrocesso inconstitucional e possibilitará a deflagração da onda de indexação de recursos financeiros ao número de candidatas lançadas, como se comenta adiante.

Ainda em 2015, em 12 de março, adveio a Proposta de Emenda à Constituição - PEC $\mathrm{n}^{0}$ 23, de autoria da Senadora Vanessa Grazziotin, cuja redação original previa que "seriam reservadas pelo menos 30\% das vagas para mulheres. Esse número seria aumentado em cinco pontos percentuais a cada eleição, até chegar a 50\%”²0. O objetivo era acrescentar o artigo 16A à Constituição brasileira, para determinar a paridade de gênero nos assentos de todas as casas parlamentares. Em 05 de maio do mesmo ano o projeto sofreu emenda do Senador Antônio Anastasia, barrando a oferta de paridade e fixando cota idêntica à de registro, 30\% dos assentos, em incrível salto para trás. Nota-se, aqui, o apego à proposta inicial de formação de massa crítica feminina em número da década de 1970 do século passado, sem rendição à pósmodernidade (DAHLERUP, 1999).

Desde dezembro de 2015, sob relatoria da Senadora Simone Tebet, que já exarou voto pela aprovação, essa PEC se encontra pronta para ser levada à pauta, mas sofre de letargia compreensível num universo de maioria masculina sem compromisso com a democracia paritária.

\subsection{AIME e a AIJE para o controle da fraude na cota de gênero: a onda jurídica}

A despeito do vigor legal acerca da cota de gênero para o registro de candidatas desde 1995, somente vinte anos depois é que a jurisprudência fixou a possibilidade de se apurar seu simulacro como fraude, por meio de ações judiciais eleitorais.

Com esse salto epistemológico se inaugurou a quarta onda no direito político da mulher, com o reconhecimento do iter procedimental, a cargo do judiciário, para a defesa das cotas de gênero.

\footnotetext{
${ }^{20}$ BRASIL. Mulheres poderão vir a ter 30\% das vagas na Câmara dos Deputados. Disponível em: <https://www12.senado.leg.br/noticias/materias/2017/01/23/mulheres-poderao-vir-a-ter-30-das-vagas-nacamara-dos-deputados>. Acesso em: 30 mar. 2018.
} 
Fala-se aqui de duas decisões tomadas no Tribunal Superior Eleitoral que admitiram a Ação de Impugnação de Mandato Eletivo - AIME e a Ação de Investigação Judicial Eleitoral - AIJE como aptas a apurar abuso do poder político, econômico e fraude na violação das cotas.

A primeira a decisão, em 04 de agosto de 2015, foi prolatada no Recurso Eleitoral Especial $n^{\circ} 1-49.2013 .6 .18 .0024$, reconhecendo que:

(...)

2. O conceito da fraude, para fins de cabimento da ação de impugnação de mandato eletivo (art. 14, § 10, da Constituição Federal), é aberto e pode englobar todas as situações em que a normalidade das eleições e a legitimidade do mandato eletivo são afetadas por ações fraudulentas, inclusive nos casos de fraude à lei. A inadmissão da AIME, na espécie, acarretaria violação ao direito de ação e à inafastabilidade da jurisdição. (BRASIL, 2015, online).

Dessa forma o TSE definiu que a AIME engloba o exame de todas as situações que possam afetar a normalidade das eleições e a legitimidade do mandato obtido, não se admitindo qualquer interpretação restritiva do art. 14 , § 10, da Constituição, sob pena de se retirar esse direito fundamental de ação que também é das mulheres.

Na oportunidade do julgamento, se realçou importante ação para defesa da cota de gênero eis que só se pode aferir a real atuação dos candidatos e candidatas após o resultado do pleito, como dito pela Ministra Luciana Lóssio:

Se não admitirmos que a Justiça Eleitoral tenha conhecimento na Ação de Impugnação de Mandato Eletivo, essa fraude não chegará à apreciação da Justiça, porque na impugnação do Demonstrativo de Regularidade de Atos Partidários (DRAP), tal fraude ainda não é do conhecimento de ninguém, ou seja, esse tipo de ardil ficará impune. (BRASIL, 2015, online).

A segunda decisão foi tomada cerca de um ano depois, em 16 de agosto de 2016, no Recurso Especial Eleitoral de $n^{\circ}$ 243-42.2012.6.18.0024, ainda mais direta e objetiva que a anterior:

(...)

4. É possível verificar, por meio da ação de investigação judicial eleitoral, se o partido político efetivamente respeita a normalidade das eleições prevista no ordenamento jurídico - tanto no momento do registro como no curso das campanhas eleitorais, no que tange à efetiva observância da regra prevista no art. 10, § $3^{\circ}$, da Lei das Eleições - ou se há o lançamento candidaturas apenas para que se preencha, em fraude à lei, o número mínimo de vagas previsto para cada gênero, sem o efetivo desenvolvimento das candidaturas.

5. Ainda que os partidos políticos possuam autonomia para escolher seus candidatos e estabelecer quais candidaturas merecem maior apoio ou destaque na propaganda 
eleitoral, é necessário que sejam assegurados, nos termos da lei e dos critérios definidos pelos partidos políticos, os recursos financeiros e meios para que as candidaturas de cada gênero sejam efetivas e não traduzam mero estado de aparências. (...) (BRASIL, 2016, online)

Ao admitir as ações pertinentes, o TSE andou muito bem, mas não se ignora que esses procedimentos judiciais não são abertos à coletividade (apenas a candidatos, partidos, coligações e Ministério Público), ademais de não se ter, com clareza legal, os elementos componentes do conceito de fraude na cota de gêneros ${ }^{21}$.

O reconhecimento de tais ações para a defesa dos direitos políticos das mulheres exige, em complementação, que se busque formação de teoria democrática para a legitimação do agir no processo eleitoral, com a inclusão dos cidadãos e das cidadãs, assim como de instituições

\footnotetext{
${ }^{21}$ V.g., recentemente, na $132^{\mathrm{a}}$ Zona Eleitoral de Passabém, em Minas Gerais, cassaram-se os mandatos de cinco Vereadores, dentre eles a mulher mais bem votada da Cidade, porque se entendeu haver fraude diante do número pequeno de votos obtidos por determinada candidata, mesmo a sentença reconhecendo que não há mínimos prescritos em lei que, respeitados, afastem essa pretensa fraude. Leia-se como publicada a sentença, com laivos machistas ante a punição da mulher que só obteve cinco votos, sem condenar a falta de recursos suficientes para que ela pudesse fazer campanha melhor:
}

(...)

A comprovação da candidatura fictícia em tela não decorre apenas do fato de determinada candidata ter obtido votação pífia, com apenas 05 (cinco) votos, e não ter havido gasto em campanha. O contexto fático que motivou o investigante diz respeito a uma coligação partidária a que se atribui o lançamento de 5 (cinco) candidaturas do sexo feminino, das quais 1 (uma) sequer praticou atos de campanha, dividindo, em tese, a sua base eleitoral com duas pessoas de sua família.

De fato, inexiste na legislação brasileira atos de propaganda mínimos que tenham de ser desempenhados por cada candidato durante a campanha eleitoral. No entanto, pelos depoimentos prestados, a Sra. (...), certamente não desejava ser candidata e não fez esforço nenhum para tal, porque era tão somente "figurante", uma típica candidata "fantasma".

(...)

Ressalte-se que desconstituir os mandatos eletivos dos titulares e suplentes, com exceção da Sra. (...), única mulher eleita da Coligação investigante, conforme requerido pelo Ministério Público Eleitoral nas alegações finais, configuraria afronta ao art. 10, $\S 3^{\circ}$ da Lei 9.504/97, uma vez que se a Coligação não conseguiu preencher o percentual de cota de gênero necessário ao deferimento do registro de candidatura, significa que todos os seus candidatos não seriam admitidos a registro, e portanto, nem sequer poderiam ter concorrido ao pleito. Daí que outra não é a solução senão a anulação de todos os votos atribuídos à Coligação, inclusive, da mulher eleita, tendo em vista o vício que macula a coligação desde a sua origem.

Importante destacar que, no contexto fático apresentado, não há que se falar em abuso de poder político ou econômico perpetrado pelo candidato a prefeito (...), candidato a prefeito pela Coligação Investigada. Isso porque o simples fato de ter doado o valor irrisório de $\mathrm{R} \$ 76,67$ (setenta e seis reais e sessenta e sete centavos) a uma das candidatas investigadas, assim como o fez a todos os candidatos da coligação, em nada interfere no vício de percentual de gênero inobservado. Logo, a referida doação do candidato a prefeito é lícita e os atos por ele praticados não apresentam nexo causal com a candidatura fictícia em comento.

(...) (BRASIL. Tribunal Regional Eleitoral de Minas Gerais. Recurso Eleitoral no 1224-37, Passabém, Minas Gerais, sentença publicada no Diário do Judiciário eletrônico do Tribunal Regional Eleitoral de Minas Gerais de 06 de abril de 2017. Disponível em:<http://inter03.tse.jus.br/sadpPush/RecuperaArquivo.do>. Acesso: 29 mar. 2018. 
variadas de defesa das mulheres, além dos legitimados tradicionais. Outra meta importante envolve a construção do conceito jurídico de fraude nas cotas de gênero.

\subsection{A indexação de cotas de candidaturas femininas ao correspondente percentual de recursos do Fundo Partidário e do Fundo Especial de Financiamento de Campanha: a onda econômica de recursos públicos}

Os números apresentados nas eleições anteriores, quando já vigentes cotas de gênero, não deixam dúvidas que essa ação afirmativa, sem a garantia de outros mecanismos para fazêlas valer, como recursos financeiros, acesso à gestão partidária e visibilidade feminina nos espaços de poder, não atenderá ao ideal de igualdade substancial e não gerará pluralismo político e cidadania (SPOHR, MAGLIA, MACHADO e OLIVEIRA, 2016). Sem esses anunciados baluartes do Estado Democrático de Direito (art. $1^{\circ}$, II, V), igualdade substancial, pluralismo político e cidadania, não se concebe processo duradouro de mudanças.

Possivelmente premido pelo quadro número posto no preâmbulo deste trabalho, julgando procedente a Ação Direta de Inconstitucionalidade n ${ }^{0} 5617$, ofertada pela Procuradoria Geral da República, o Supremo Tribunal Federal brasileiro resolveu:

(...) dar interpretação conforme à Constituição ao art. $9^{\circ}$ da Lei 13.165/2015 de modo a (a) equiparar o patamar legal mínimo de candidaturas femininas (hoje o do art. 10, $\S 3^{\circ}$, da Lei 9.504/1997, isto é, ao menos 30\% de cidadãs), ao mínimo de recursos do Fundo Partidário a lhes serem destinados, que deve ser interpretado como também de 30\% do montante do Fundo alocado a cada partido, para as eleições majoritárias e proporcionais, e (b) fixar que, havendo percentual mais elevado de candidaturas femininas, o mínimo de recursos globais do partido destinados a campanhas lhe seja alocado na mesma proporção; $(. . .)^{22}$

Essa decisão permite indexar o percentual de candidaturas femininas ao correspondente percentual em recursos do Fundo Partidário e do novel Fundo Especial de Financiamento de Campanha, inaugurando a quinta onda que impacta os direitos políticos da mulher. Ao fazê-lo, em longa sessão de julgamento realizada em 15 de março de 2018, sob a relatoria do Ministro Edson Facchin, o Supremo Tribunal Federal reconheceu as seguintes premissas para tratamento do direito político em tela:

\footnotetext{
${ }^{22}$ BRASIL. Supremo Tribunal Federal. Ação Direta de Inconstitucionalidade $n^{\circ}$ 5.167/DF. Relator: Ministro Edson Facchin. Brasília. Sessão de julgamento de 15 de março de 2018. Disponível em: $<$ https://www.youtube.com/watch?v=-P7TrXk63Zs>.
} 
Primeira: As ações afirmativas prestigiam o direito à igualdade.

Segunda: É incompatível com o direito à igualdade a distribuição de recursos públicos orientada apenas pela discriminação em relação ao sexo da pessoa.

Terceira: A autonomia partidária não consagra regra que exima o partido do respeito incondicional aos direitos fundamentais, especialmente ao direito á igualdade.

Quarta: a igualdade entre homens e mulheres exige não apenas que as mulheres tenham garantidas iguais oportunidades, mas também que sejam elas empoderadas por um ambiente que as permita alcançar a igualdade de resultados.

Quinta: a participação das mulheres nos espaços políticos é um imperativo do Estado, uma vez que a ampliação da participação pública feminina permite equacionar as medidas destinadas ao atendimento das demandas sociais das mulheres. ${ }^{23}$

Observa-se, para refletir sobre a onda inexorável de paridade, que conquanto o Supremo Tribunal Federal tenha afirmado a premissa da igualdade, não se conseguiu avançar para além do discurso patriarcal de manutenção do statu quo, ainda preso ao limite imposto na década de 1970 do século passado para formação de massa crítica, sem atenção ao fundamento constitucional atual que se quis aplicar. A despeito da linguagem, se observa o aprisionamento de limites inferiores ao ideal constitucional.

Nessa mesma onda, formulada pela Senadora Lídice da Mata e Souza, tramita no TSE a Consulta $n^{0}$ 0603816-39.2017.6.00.0000, relatada pela Ministra Rosa Weber, por meio da qual se objetiva que a cota de gênero prevista no $\S 3^{\circ}$ do artigo 10 da lei 9.504 se estenda às comissões executivas e aos diretórios dos partidos políticos. Sem tal mínimo, a pretensão é que não se aceite registro das direções partidárias.

É bom que se diga que o Ministério Público Federal, embora autor da ADI n ${ }^{\circ}$ 5.617, em franca contradição, exarou parecer negativo à fixação de cotas de gênero nas direções partidárias porque diz não haver regra expressa para tanto, se esquecendo do conteúdo imperativo de igualdade que dá fundamento à República.

A importância da resposta afirmativa a essa consulta é que a inserção das mulheres nas direções partidárias permitirá que se busquem resultados concretos com a gestão de recursos direcionados às políticas de promoção e inserção delas na política, ainda que na versão minimalista.

\section{COTAS E IGUALDADE SUBSTANCIAL: PARTIDA E CHEGADA}

\footnotetext{
${ }^{23}$ BRASIL. Supremo Tribunal Federal. Ação Direta de Inconstitucionalidade $n^{\circ}$ 5.167/DF. Relator: Ministro Edson Facchin. Brasília. Sessão de julgamento de 15 de março de 2018. Disponível em: $<$ https://www.youtube.com/watch?v=-P7TrXk63Zs>.
} 
A defesa de cotas de gênero, todavia, não pode encerrar a luta feminista por ocupação dos espaços de poder, nem revelar a qualidade do processo eleitoral que se queira democrático. Como já dito em outra oportunidade, “cotas, importante começo, não são fim, nem servem apenas para destinar um lugar para as mulheres ou para cumprir metas perante a comunidade internacional” (LOBO, 2016, 9. 49).

Até porque, “é crucial superar o modelo de cotas, para evoluir rumo à paridade, desde já adotando a rotatividade em cargos de direção nas entidades ou instituições em que atuem mulheres e homens, respeitadas as exigências, quando necessárias, de qualificação técnica” (LOBO, 2016, p. 50).

Com efeito:

A possibilidade de transformação da situação brasileira não se encerra no direito eleitoral. Necessita, antes de tudo, da implantação do processo histórico de longa duração para formação de consciências, extirpando da educação formal e informal o preconceito introjetado pelos donos do poder, de que a mulher não é capaz, não se interessa pelo público e tem lugar definido, bela e recatada, no ambiente confortável do lar. ${ }^{24}$

A igualdade material que sustenta sociedade verdadeiramente democrática não pode se contentar com a política de cotas sem fixar meta temporal para atingir paridade absoluta nos espaços públicos de poder, registrando a próxima onda a nortear o direito político das mulheres. Nessa direção, a atual redação dada pela comentada PEC 23, de 2015, desserve ao referente de igualdade substancial e acaba por delimitar o espaço das mulheres em percentual inferior a um terço, numa espécie de gueto para mantê-las limitadas ao quanto estabelecido pelo poder patriarcal.

Adriana Medina Espino alerta que:

Las cuotas de género deben inscribirse en el marco de proyectos integrales de polí-
tica pública que fortalezcan el liderazgo efectivo de las mujeres, lo que implica reco-
nocer que requieren ir acompañadas de políticas públicas tendientes a lograr la
igualdad de oportunidades. No debe perderse de vista que el problema subyacente es
la transformación de la cultura política (y con ello el sistema social de género) que
sostiene y alimenta la discriminación hacia las mujeres.
La reflexión en torno a las cuotas de género ha llevado a repensar en otras medidas
que contribuyan a cerrar las brechas de desigualdad entre mujeres y hombres y avan-
zar hacia una democracia de género a través del respeto al liderazgo, el empodera-

${ }^{24}$ LÔBO, Edilene A paridade como direito fundamental da democracia substancial no Brasil: Mulher na Política. In: Teorias da Democracia e Direitos Políticos (Org. CONPEDI). V Encontro Internacional do CONPEDI. Uruguai, Montevidéu, 8 a 10 de setembro de 2016, p. 50. Disponível em: $<$ https://www.conpedi.org.br/publicacoes/9105o6b2/a53306ij/7JlDuV5xa1KMtNML.pdf >. Acesso: 28 mar. 2018. 
miento y la ciudadanía de las mujeres, así como el mejoramiento sustancial en la calidad de la democracia. En este proceso, la paridad se distingue por ser un tema que ha cobrado auge en los años recientes. ${ }^{25}$

É de se lembrar que desde agosto de 2007, com o Consenso de Quito, na Décima Conferência Regional Sobre a Mulher da América Latina e Caribe (CEPAL-ONU), ficou combinado:

Adoptar todas las medidas de acción positiva y todos los mecanismos necesarios, incluidas las reformas legislativas necesarias y las asignaciones presupuestarias, para garantizar la plena participación de las mujeres en cargos públicos y de representación política con el fin de alcanzar la paridad en la institucionalidad estatal (poderes ejecutivo, legislativo, judicial y regímenes especiales y autónomos) y en los ámbitos nacional y local, como objetivo de las democracias latinoamericanas y caribeñas; ${ }^{26}$

Essa ação afirmativa já contava com a tática importante dentre tantas ali desenvolvidas para consecução da paridade:

Desarrollar políticas electorales de carácter permanente que conduzcan a los partidos políticos a incorporar las agendas de las mujeres en su diversidad, el enfoque de género en sus contenidos, acciones y estatutos y la participación igualitaria, el empoderamiento y el liderazgo de las mujeres, con el fin de consolidar la paridad de género como política de Estado; ${ }^{27}$

Três anos depois, com o Consenso de Brasília, na Undécima Conferência Regional Sobre a Mulher da América Latina e Caribe, também ficou decidido:

(...) promover la creación de mecanismos y apoyar los ya existentes para assegurar la participación político-partidaria de las mujeres que, además de la paridad em los registros de candidaturas aseguren la paridade em los resultados, el acceso igualitario al financiamento de campanas y a la propaganda electoral, y la inserción equitativa em los espacios ded decisión dentro de las estructuras de los partidos políticos. ${ }^{28}$

\footnotetext{
${ }^{25}$ ESPINO, Adriana Medina. La participación política de las mujeres. De las cuotas de género a la paridade. México: Centro de Estudios para el Adelaneto de Las Mujeres y La Equidade de Género (CEAMEG), Congresso de la Unión Cámara de Diputados. LXI Legislatura, 2010, p. 25.

${ }^{26}$ ONU- CEPAL. X Conferência Regional sobre la Mujer de America Latina y el Caribe. Consenso de Quito. 09 de agosto de 2007. Disponível em: < https://www.cepal.org/publicaciones/xml/9/29489/dsc1e.pdf >. Acesso: 01 abr. 2018.

${ }^{27}$ ONU- CEPAL. X Conferência Regional sobre la Mujer de America Latina y el Caribe. Consenso de Quito. Equador: 09 de agosto de 2007. Disponível em: < https://www.cepal.org/publicaciones/xml/9/29489/dsc1e.pdf >. Acesso: 01 abr. 2018.

${ }^{28}$ ONU- CEPAL. XI Conferência Regional sobre la Mujer de America Latina y el Caribe. Consenso de Brasilia. Brasil: 16 de julio de 2010. Disponível em:

<https://www.cepal.org/mujer/noticias/paginas/5/40235/ConsensoBrasilia_ESP.pdf>. Acesso: 01 abr. 2018.
} 
No Consenso de Santo Domingo, em 2013, na Décima Terceira Conferência Regional Sobre a Mulher da América Latina e Caribe, realizada no Uruguai em outubro de 2016, estabeleceu-se com a Estratégia de Montevidéu “uma aposta política para alcançar a igualdade de gênero até 2030 ”29.

Deste documento se confere importante retrospectiva histórica a ser relembrada para que não se perca de vista o compromisso firmado há pelo menos 30 anos no Brasil com a Constituição, e ainda em passos iniciais cambaleantes com a busca de cotas para conferir algum espaço de poder para as mulheres, situação que urge por modificação radical.

No âmbito da região da América Latina e Caribe, há 40 anos se amealham esforços para a construção de uma agenda voltada à paridade desde a Primeira Conferência, sucedida em Havana, no ano de 1977.

Essa agenda regional deve ser tratada como ferramenta à alavancagem da visibilidade da luta das mulheres, capaz de propiciar articulação entre os vários organismos no plano nacional e internacional, forçando os Estados a firmarem documentos públicos que materializem o repúdio à discriminação e se voltem para a erradicação da desigualdade como resistência à barbárie.

Dos vários documentos internacionais construídos para essa agenda, é frequente “um término sócio-político-jurídico que se basa en la ciudadania activa y pretende traducir la igualdad de oportunidade en una igualdad de resultado” (OBANDO, 2016, p. 147), que não pode ser ignorado.

A busca pela igualdade de resultados, portanto, não se compadece do sistema de cotas como única ratio, porque este se volta para a delimitação de espaço muito próximo ao que se tem na atualidade e, como antevisto, não atende ao referencial constitucional de igualdade material. Além das cotas, há que se expurgar "la exclusión estructural de las mujeres y restlabeciendo uan democracia de gênero” (OBANDO, 2016, p. 147), o que se apresenta como meta a ser atingida para que não se adie mais a promessa constitucional anotada desde a segunda onda de direitos políticos das mulheres.

${ }^{29}$ ONU-CEPAL. XIII Conferência Regional sobre la Mujer de America Latina y el Caribe. Estrategia de Montevideo para la implementación de la Agenda Regional de Género em el Marco del Desarollo Sostenible hacia 2030. Uruguay: 28 de octubre de 2016. Disponivel em: $<$

https://www.cepal.org/sites/default/files/events/files/estrategia_de_montevideo_para_la_implementacion_de_la_ agenda_regional_de_genero_en_el_marco_del_desarrollo_sostenible_hacia_2030_0.pdf $>$. Acesso em: 01 abr. 2018. 


\title{
3 O ESTATUTO POLÍTICO DAS MULHERES
}

No Estado de Direito, mais ainda no sistema brasileiro da civil law, a fixação de regras escritas e sua interpretação pelos tribunais dão o conjunto normativo que desenha o ordenamento, coroado pela Constituição.

Orientado pelo paradigma democrático, o conjunto atual envolvendo o direito político das mulheres se encontra de tal modo composto que já pode ser reconhecido e estudado como disciplina autônoma, até para que se apresente como mais um mecanismo para corroboração das ações afirmativas voltadas à inclusão da mulher na política.

Tereza Pizarro Beleza explica essa importância:

\begin{abstract}
Olhar e pensar o estatuto jurídico das mulheres, refletir sobre a sua condição jurídico social, implica compreender a sua construção relacional, por contraposição à dos homens, que assim também se auto-define numa contraposição hierarquizada. O Direito em muito contribuiu historicamente para a construção dessa divisão bipolar desigual, assimétrica. Isto é, há uma importante dimensão jurídica da construção das relações sociais de gênero. ${ }^{30}$
\end{abstract}

Nessa linha, reconhecer o estatuto político das mulheres é corroborar as lutas renhidas pela busca de espaços sociais de reconhecimento e de visibilidade, combatendo a gênese excludente da sociedade capitalista machista.

Esse reconhecimento permitirá reunir e organizar o estudo da legislação voltada para a participação da mulher na vida política nacional, fazendo com que sua explicitação, inclusive com os respectivos deficits, oportunize construção do espírito crítico e novas possibilidades para que homens e mulheres se irmanem na travessia pela vida boa para todos, todas e todes, como propõe Márcia Tiburi ${ }^{31}$.

\section{CONCLUSÕES}

Os direitos políticos das mulheres no Brasil sofreram impactos das ondas referidas ao longo do trabalho, mas ainda não são capazes de permitir a eliminação da desigualdade abissal

\footnotetext{
${ }^{30}$ BELEZA, Tereza Pizarro. O direito das mulheres e da igualdade social: a construção jurídica das relações de gênero. Edições Almedinas: Coimbra, 2010, p. 28.

${ }^{31}$ TIBURI, Márcia. Feminismo em comum: para todas, todes e todos. $1^{\text {a }}$ ed. Rio de Janeiro: Rosa dos Tempos, 2018.
} 
entre homens e mulheres no plano concreto da vida política, porque faltam mecanismos que assegurem resultados concretos.

Analisando-se a política de cotas de gênero no registro de candidaturas conclui-se que ela não é capaz, per se, sem acesso aos recursos públicos, de garantir resultados na mesma proporção fixada, situação que ganha novos contornos com a indexação a recursos do Fundo Partidário e do Fundo Especial de Financiamento de Campanha, determinada pelo STF no julgamento da ADI 5617.

Cotas de gênero compõem ponto de partida rumo à paridade, orientando novas interpretações da legislação à luz da Constituição, dando-se eficácia aos documentos internacionais que estabelecem marco temporal para tanto, saltando da massa crítica da década de 1970 para se inserir no pós-mundo da era tecnológica do novo milênio.

O reconhecimento do estatuto político das mulheres corrobora a reunião e a organização da legislação e sua interpretação hermenêutica, oportunizando o estudo especializado do tema, voltando-se ao paradigma constitucional de erradicação da discriminação para promoção do bem coletivo, em desapego aos números que limitem a partilha igualitária da vida boa prometida.

\section{REFERÊNCIAS BIBLIOGRÁFICAS}

BAPTISTA, Rodrigo. Cresce percentual de mulheres entre Senadores eleitos. Brasília: Senado, 06 de outubro de 2014.2 Disponível em:< https://www12.senado.leg.br/noticias/materias/2014/10/06/cresce-percentual-de-mulheresentre-senadores-eleitos>.

BARROSO, Luís Roberto. A judicialização da vida e o papel do Supremo Tribunal Federal, Belo Horizonte: Fórum, 2018.

BELEZA, Tereza Pizarro. O direito das mulheres e da igualdade social: a construção jurídica das relações de gênero. Edições Almedina: Coimbra, 2010.

BIROLI, Flávia. Gênero e desigualdades: limites da democracia no Brasil. Rio de Janeiro: Boitempo, 2018.

BRASIL. Decreto $n^{\circ}$ 21.076, de 24 de fevereiro de 1932. Decreta o Código Eleitoral. Publicado no Rio de Janeiro, no Diário Oficial da União de 26 de fevereiro de 1932. Disponível em:< 
http://www2.camara.leg.br/legin/fed/decret/1930-1939/decreto-21076-24-fevereiro-1932507583-publicacaooriginal-1-pe.html>.

BRASIL. Constituição Federal. Publicada em Brasília, no Diário Oficial da União de 05 de outubro de 1988.

Disponível em:<http://www.planalto.gov.br/ccivil_03/constituicao/constituicao.htm>.

BRASIL. Lei $n^{\circ}$ 9.096, de 19 de setembro de 1995. Dispõe sobre os partidos políticos. Diário Oficial da União. Brasília, DF, 20 jun. 1995. Disponível em: $<$ http://www.planalto.gov.br/ccivil_03/leis/L9096.htm >.

BRASIL. Lei $n^{o}$ 9.100, de 29 de setembro de 1995. Estabelece normas para as eleições municipais de 03 de outubro de 1996. Diário Oficial da União. Brasília, DF, 02 out. 1995. Disponível em: < http://www.planalto.gov.br/ccivil_03/leis/L9100.htm>.

BRASIL. Lei $n^{\circ}$ 9.504, de 30 de setembro de 1997. Estabelece normas para as eleições. Diário Oficial da União. Brasília, DF, $1^{\text {o }}$ out. 1997. Disponível em: <http://www.planalto.gov.br/ccivil_03/leis/L9504.htm>.

BRASIL. Lei $n^{\circ}$ 12.034, de 29 de setembro de 2009. Altera as leis $n^{\circ}$ 9.906, de 19 de setembro de 1995, 9.504, de 30 de setembro de 1997 e 4.737, de 15 de julho de 1965 - Código Eleitoral. Diário Oficial da União. Brasília, DF, 30 set. de 2009. Disponível em: <http://www.planalto.gov.br/ccivil_03/_ato2007-2010/2009/lei/l12034.htm>.

BRASIL. Câmara dos Deputados. Bancada feminina cresce de 45 para 51 Deputadas. Relatório divulgado em 06 de outubro de 2014. Disponível em:< http://www2.camara.leg.br/camaranoticias/noticias/POLITICA/475459-BANCADA-

FEMININA-CRESCE-DE-45-PARA-51-DEPUTADAS.html >.

BRASIL. Mulheres poderão vir a ter 30\% das vagas na Câmara dos Deputados. Disponível em:<https://www12.senado.leg.br/noticias/materias/2017/01/23/mulheres-poderao-vir-a-ter30-das-vagas-na-camara-dos-deputados>. Acesso em: 30 mar. 2018.

BRASIL. Lei $n^{\circ} 13.165$, de 29 de setembro de 2015. Altera as leis $n^{\circ}$ 9.906, de 19 de setembro de 1995, 9.504, de 30 de setembro de 1997 e 4.737, de 15 de julho de 1965 - Código Eleitoral, para reduzir os custos das campanhas eleitorais, simplificar a administração dos Partidos Políticos e incentivar a participação feminina. Diário Oficial da União. Brasília, DF, 29 set. de 2015. Disponível em: <http://www.planalto.gov.br/ccivil_03/_ato20152018/2015/lei/113165.htm>. 
BRASIL. Tribunal Superior Eleitoral. Recurso Especial Eleitoral $n^{\circ}$ 1-49/PI. Relator Ministro Henrique Neves da Silva. Dário do Judiciário eletrônico, Brasília, 21 de outubro de 2015. Disponível em:< http://www.tse.jus.br/jurisprudencia/decisoes/jurisprudencia > .

BRASIL. Tribunal Superior Eleitoral. Recurso Especial Eleitoral $n^{\circ}$ 243-42. Relator Ministro Henrique Neves da Silva. Dário do Judiciário eletrônico, Brasília, 11 de outubro de 2016. Disponível em: < http://www.tre-mg.jus.br/jurisprudencia/pesquisa/consulta>.

BRASIL. Tribunal Regional Eleitoral de Minas Gerais. Recurso Eleitoral nº 1224-37, Passabém, Minas Gerais, sentença publicada no Diário do Judiciário eletrônico do Tribunal Regional Eleitoral de Minas Gerais de 06 de abril de 2017. Disponível em:<http://inter03.tse.jus.br/sadpPush/RecuperaArquivo.do>. Acesso: 29 mar. 2018. BRASIL. Supremo Tribunal Federal. Ação Direta de Inconstitucionalidade $n^{\circ}$ 5.167/DF. Relator: Ministro Edson Facchin. Brasília. Sessão de julgamento de 15 de março de 2018. Disponível em: <https://www.youtube.com/watch?v=-P7TrXk63Zs>.

CAIXA DE ASSISTÊNCIA DOS ADVOGADOS DE MINAS GERAIS. Mulher advogada: igualdade ou o machismo perdura? Disponível em: < https:/www.caamg.org.br/mulheradvogada-igualdade>. Acesso em 27 mar. 2018.

CAPES. Estudo aponta que mulheres lideram número de doutores titulados no exterior. Disponível em: < https://capes.gov.br/component/content/article/36salaimprensa/noticias/7852-estudo-aponta-que-mulheres-lideram-numero-de-doutorestitulados-no-exterior>. Acesso em: 29 mar. 2018.

CASTRO, Carmén Lúcia Freitas de; GONTIJO, Cynthia Rúbia Braga; DIAS, Darli de Souza (Orgs.) Políticas Públicas de Educação: a inclusão e a diversidade. Barbacena: Editora da Universidade do Estado de Minas Gerais, 2015.

CAVALLINI, Marta. Mulheres ganham menos que os homens em todos os cargos e áreas. O Globo: Portal G1, Rio de Janeiro, 2018. Disponível em:<https://g1.globo.com/economia/concursos-e-emprego/noticia/mulheres-ganham-menosque-os-homens-em-todos-os-cargos-e-areas-diz-pesquisa.ghtml>.

CEREZALES, Diego Palacios. Assinem assinem, que a alma não tem sexo! Petição coletiva e cidadania feminina no Portugal constitucional (1820-1910). Lisboa: Revista Análise Social, 205, XXLVII (4 $\left.4^{\circ}\right), 2012$. 
DAHLERUP, Drude. De uma pequena a uma grande minoria: uma teoria da "massa crítica" aplicada ao caso das mulheres na política escandinava. In: LAMAS, M. (Org.). Debate feminista: cidadania e feminismo. São Paulo: Melhoramentos, 1999, p. 142-183.

ESPINO, Adriana Medina. La participación política de las mujeres. De las cuotas de género a la paridade. México: Centro de Estudios para el Adelaneto de Las Mujeres y La Equidade de Género (CEAMEG), Congresso de la Unión Cámara de Diputados. LXI Legislatura, 2010 GURGEL, Yara Maria Pereira. Direitos humanos, princípio da igualdade e não discriminação: sua aplicação às relações de trabalho. São Paulo: LTR, 2010.

IDDH-Instituto Interamericano de Derechos Humanos. Derechos políticos de las mujeres: avances e buonas praticas em El Salvador, Costa Rica y Pananá. IDDH: San Jose, Costa Rica, 2016.

KEANE, John. Vida e morte da democracia. Almedina Brasil: São Paulo, 2010.

LISBOA, Silvia; GONSÁLEZ, Leticia. Justiça Machista-Quando as mulheres têm uma dupla condenação: pelo crime e pelo gênero. São Paulo: Revista Galileu, Editora Globo, Edição 320, março de 2018.

LÔBO, Edilene A paridade como direito fundamental da democracia substancial no Brasil: Mulher na Política. In: Teorias da Democracia e Direitos Políticos (Org. CONPEDI). V Encontro Internacional do CONPEDI. Uruguai, Montevidéu, 8 a 10 de setembro de 2016, p. 39-54.

Disponível

em: $<$

https://www.conpedi.org.br/publicacoes/9105o6b2/a53306ij/7JlDuV5xa1KMtNML.pdf >

LOBO, Edilene. O (des)controle judicial do impeachment. Brasilia: Universitas Jus, v. 27, $\mathrm{n}^{\circ}$ 3, 2017, p. 7-16.

MIRANDA, Jorge. Direitos Fundamentais. Coimbra: Edições Almedina: 2016.

NEISCHT, Joana. Mulheres são apenas 26,2\% da magistratura federal. Jornal Gazeta do Povo. Em 08 de março de 2018. Disponível em:< http://www.gazetadopovo.com.br/vida-p ublica/justica-e-direito/mulheres-sao-apenas-262-da-magistratura-federalf3p3x3enzs47wzpei1m9v96w3>. Acesso: 27 mar. 2018.

ONU- CEPAL. X Conferência Regional sobre la Mujer de America Latina y el Caribe. Consenso de Quito. 09 de agosto de 2007. Disponível em: < https://www.cepal.org/publicaciones/xml/9/29489/dsc1e.pdf > . Acesso: 01 abr. 2018. ONU- CEPAL. XI Conferência Regional sobre la Mujer de America Latina y el Caribe. Consenso de Brasilia. Brasil: 16 de julio de 2010. Disponível em: 
<https://www.cepal.org/mujer/noticias/paginas/5/40235/ConsensoBrasilia_ESP.pdf>. Acesso: 01 abr. 2018.

ONU-CEPAL. XIII Conferência Regional sobre la Mujer de America Latina y el Caribe. Estrategia de Montevideo para la implementación de la Agenda Regional de Género em el Marco del Desarollo Sostenible hacia 2030. Uruguay: 28 de octubre de 2016. Disponivel em: $<$

https://www.cepal.org/sites/default/files/events/files/estrategia_de_montevideo_para_la_impl ementacion_de_la_agenda_regional_de_genero_en_el_marco_del_desarrollo_sostenible_ha cia_2030_0.pdf >. Acesso em: 01 abr. 2018.

ONU. Taxa de feminicidios no Brasil é quinta maior do mundo. Publicado em 09 de abril de 2016. Disponível em: <https://nacoesunidas.org/onu-feminicidio-brasil-quinto-maior-mundodiretrizes-nacionais-buscam-solucao/>.

SANTOS, Lulu. Como uma onda no mar. Música inserida no álbum O Ritmo do Momento. Rio de Janeiro, 1983. Disponível em:< https:/www.youtube.com/watch?v=XFa73hlzR-4>. Acesso: 29 mar. 2018.

SPOHR, Alexandre Piffero; MAGLIA, Cristiana; MACHADO, Gabriel; OLIVEIRA, Joana Oliveira de. Participação Política de Mulheres na América Latina: o impacto de cotas e de lista fechada. Florianópolis: Revista de Estudos Feministas, vol. 24, n. 2, 2016.

SOSPEDA, Manuel Martínez; MARCO, Joaquín J. Marco; OTALORA, Ainhoa Uribe. Sistemas electorales: um estúdio comparado. Valencia, Espanha: Tirant lo blanch, 2007.

TIBURI, Márcia. Feminismo em comum: para todas, todes e todos. $1^{\text {a }}$ ed. Rio de Janeiro: Rosa dos Tempos, 2018. 